\title{
Correction of an animation deformity that developed from breast implant removal
}

\author{
Simon Yang, Dae Hyun Lew, Tai \\ Suk Roh, Seung Yong Song \\ Department of Plastic and Reconstructive \\ Surgery, Institute for Human Tissue \\ Restoration, Yonsei University College of \\ Medicine, Seoul, Korea
}

\begin{abstract}
Subpectoral implant insertion is considered to be the standard procedure for breast augmentation and reconstruction. However, in some patients who have undergone breast augmentation or reconstruction surgery with a prosthesis, implant removal may be required for various reasons, including infection or implant rupture. According to a literature review, the standard technique for implant removal has not been thoroughly investigated. This study aimed to report the case of a patient who developed animation deformity after implant removal and to suggest a technique for preventing such complications. A 51-year-old woman underwent breast augmentation surgery with silicone implants. However, the patient complained of an unpleasant foreign body sensation; hence, the implant was removed 6 months after the first operation. After removal of the implant, undesirable movement of the chest wall on both breasts occurred. Revision surgery under general anesthesia was planned 18 months after implant removal. Capsulectomy was performed on both sides, and the pectoralis major muscle was completely isolated and repositioned. The undesirable movement in the skin of the chest wall disappeared postoperatively. This case suggests the need for capsulectomy and repositioning of the pectoralis muscle to its original position during implant removal.
\end{abstract}

Keywords Mammaplasty / Device removal / Pectoralis muscles

\section{INTRODUCTION}

In some patients who have undergone breast augmentation or reconstruction surgery with a prosthesis, implant removal is required for various reasons, including infection, implant rupture [1], capsular contracture [2], or the patient's concern regarding breast implant-associated anaplastic large-cell lymphoma [3]. According to a literature review, the standard technique for implant removal has not been thoroughly investigated. The most common procedure

Received: May 7, 2020 Revised: May 19, 2020 Accepted: Jun 16, 2020 Correspondence: Seung Yong Song Department of Plastic and Reconstructive Surgery, Yonsei University College of Medicine, 50-1 Yonseiro, Seodaemun-gu, Seoul 03722, Korea

Tel: +82-2228-2210, Fax: +82-2-393-6947, E-mail: PSSYSONG@yuhs.ac

Copyright $\odot 2020$ The Korean Society for Aesthetic Plastic Surgery.

This is an Open Access article distributed under the terms of the Creative Commons Attribution Non-Commercial License (https://creativecommons.org/licenses/by-nc/4.0/) which permits unrestricted non-commercial use, distribution, and reproduction in any medium, provided the original work is properly cited. $\quad w w w . e-a a p s . o r g$ comprises merely opening the capsule, followed by implant removal [4]. This report presents the case of a patient who developed animation deformity after implant removal; herein, we propose a technique for preventing such complications.

\section{CASE REPORT}

A 51-year-old woman underwent breast augmentation surgery with a silicone implant at a local clinic 2 years ago. Specific information about the breast implants could not be retrieved. Nonetheless, the patient complained of an unpleasant foreign body sensation. Implant removal was performed 6 months after placement. The patient visited our outpatient clinic presenting with abnormal movement of the skin of the chest wall along with pain in both breasts. Physical examination revealed unintended motion of the medial side of the lower pole of the breast when the patient was instructed to contract the pectoralis muscle (Fig. 1, Supplemental Digital Content 1).

Revision surgery under general anesthesia was planned 18 

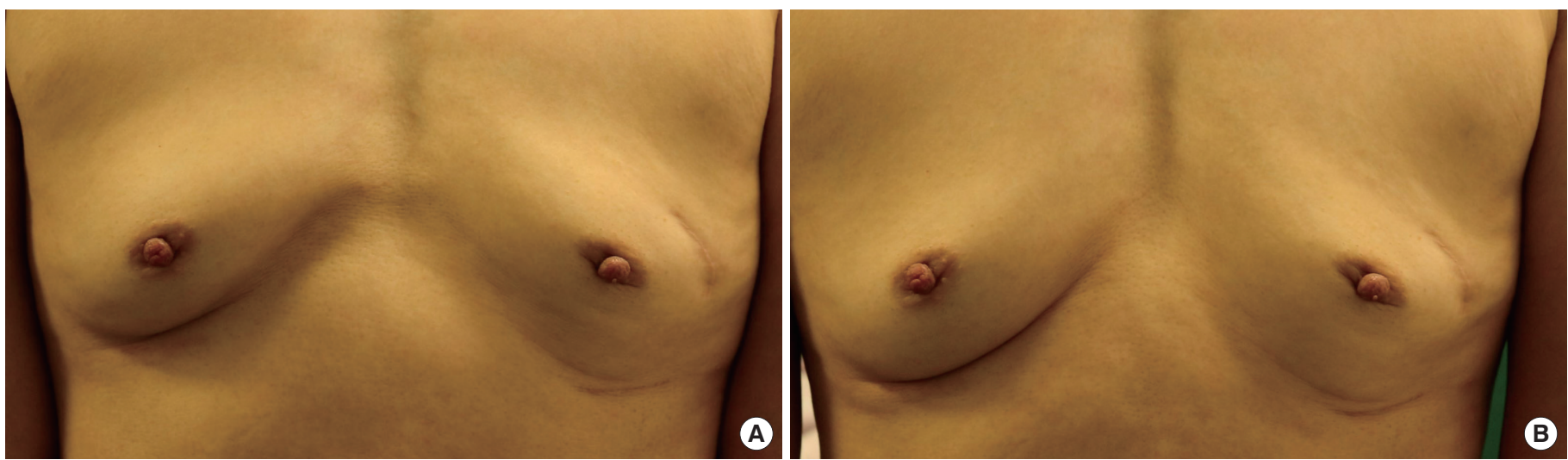

Fig. 1. Preoperative photographs. Preoperative images of the patient in the supine position. (A) Photograph of the chest wall in the relaxation state. (B) Photograph of the chest wall in the contraction state.
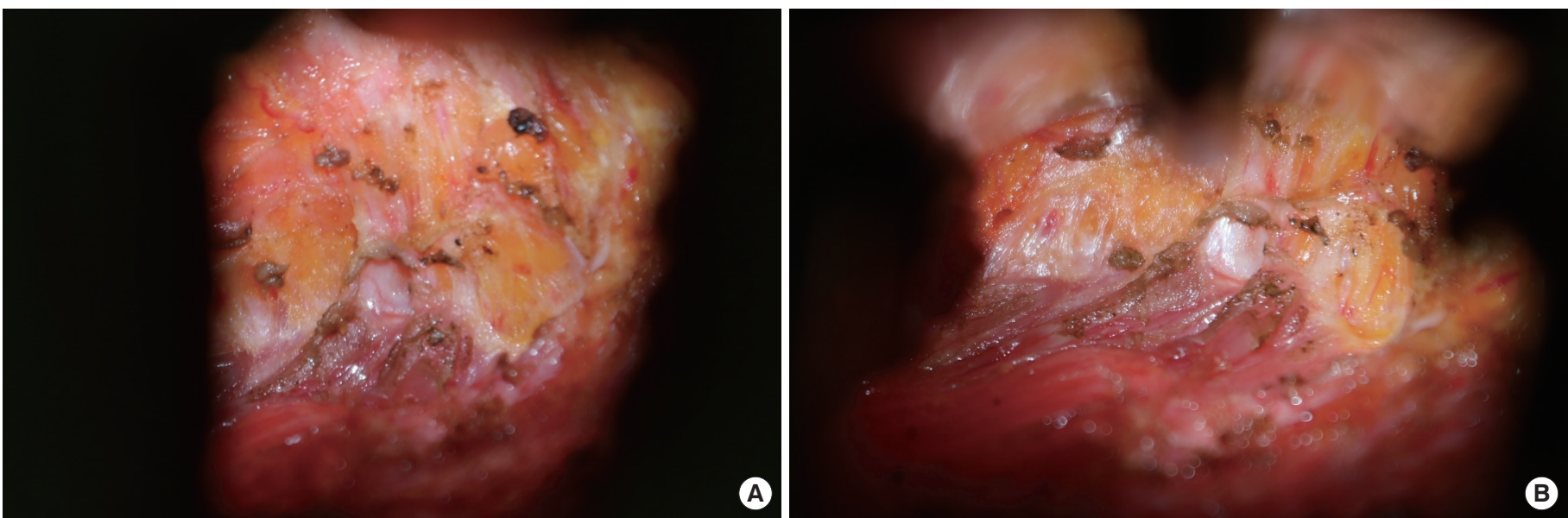

Fig. 2. Abnormal adhesion between the skin and pectoralis muscle. Intraoperative images during capsulectomy. Abnormal adhesion between the skin and pectoralis muscle is seen on $(A)$ the left and $(B)$ right breast.

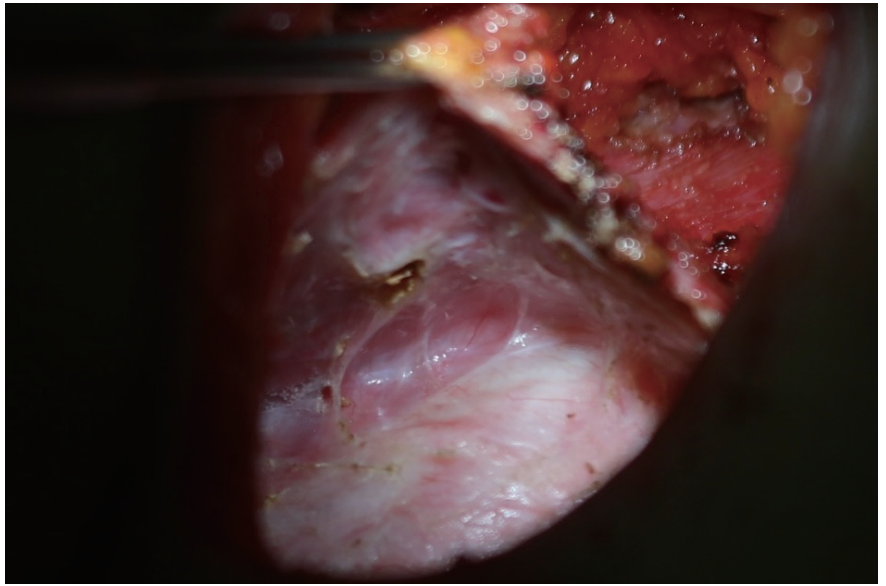

Fig. 3. Remnant capsule underneath the pectoralis muscle. During the operation, the remnant capsule is seen underneath the pectoralis muscle where the implant was located. months after implant removal. Bilateral incisions were made on the inframammary folds, which were the sites of the previous operation scars. During dissection of the pectoralis muscle from the subcutaneous tissue, abnormal adhesion was noted between the skin and pectoralis muscle (Fig. 2).

After complete dissection of the muscle and skin, the pectoralis muscle was separated from the chest wall. The remnant capsule was noted beneath the pectoralis major muscle (Fig. 3). Capsulectomy was performed on both sides, and complete isolation of the pectoralis major muscle was confirmed (Fig. 4).

After dissection, the pectoralis muscle was anchored to the chest wall using Vicryl 2-0 sutures to restore its original anatomy (Fig. 5). The patient was discharged without any complications. The patient visited the outpatient clinic 3 months postoperatively. No specific findings were observed on physical examination. The undesirable movement of the skin of the chest wall disappeared postoperatively. 

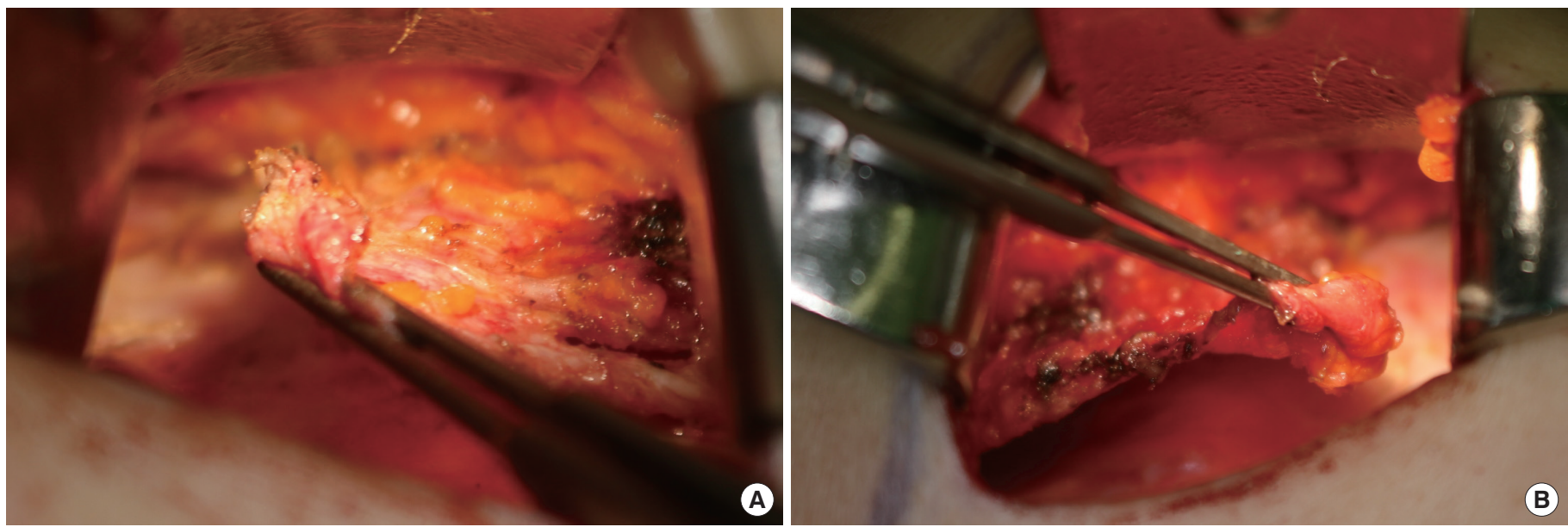

Fig. 4. Complete isolation of the pectoralis major muscle. After complete removal of the abnormal adhesion between the skin and pectoralis muscle, dissection was performed above and underneath the muscle to isolate it. (A) The left breast. (B) The right breast.

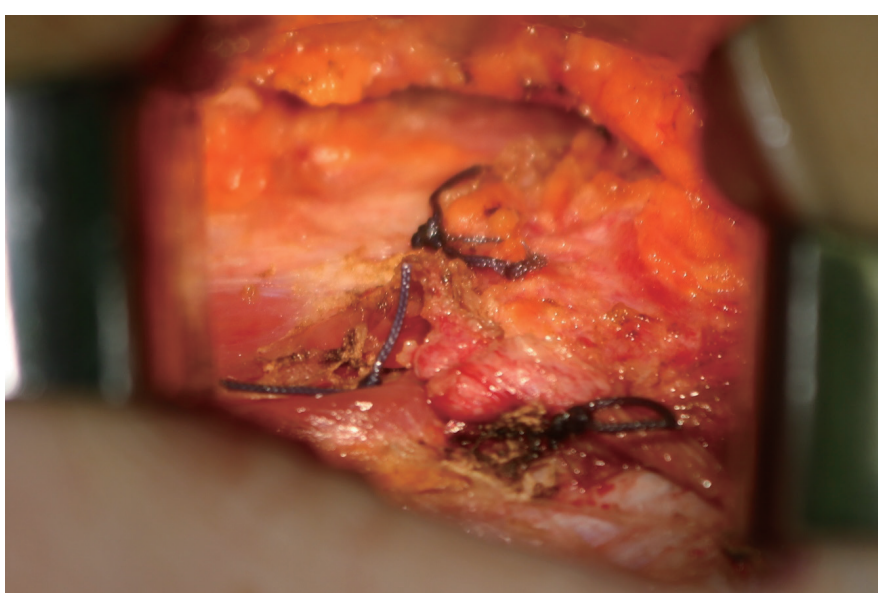

Fig. 5. Anchoring the muscle to the chest wall. After complete isolation of the pectoralis muscle, it was anchored to the chest wall to restore its original anatomy.

\section{DISCUSSION}

The procedure for anchoring the pectoralis muscle after implant removal has not been highlighted in the literature. Restoring the normal anatomy of the pectoralis major muscle and eliminating the remnant capsule after removing the breast implant has not been considered to be an essential procedure. Thomson reported that capsules surrounding implanted silicone rubber blocks disappeared within 4 weeks after explantation of the foreign body in guinea pigs [5]. However, Rockwell et al. [6] reported undissolved capsules 10 months to 17 years after removal of silicone gel breast implants in eight women. Swanson [4] reviewed the necessity of capsulectomy after breast implant removal and concluded that capsulectomy was not mandatory for asymptomatic patients considering the surgical risk and discomfort unless aplastic large-cell lymphoma is suspected. However, we considered that additional surgery was required for this patient because of the discomfort she experienced.

Breast animation deformity can occur after submuscular implant placement following breast augmentation and immediate breast reconstruction [7]. Changing the plane to prepectoral or splitting the muscle can help in the treatment of breast animation deformity [8]. Our patient complained of involuntary movement of the chest skin after breast implant removal. As the implant had already been removed, the additional procedures eliminated the remnant capsule and restored the pectoralis major muscle.

One possible explanation for this phenomenon is the formation of an abnormal adhesion between the pectoralis muscle and subcutaneous tissue, which preceded the healing between the chest wall and pectoralis muscle owing to the less adherent remnant capsule. Intraoperatively, we located the slippery surface of the previous implant pocket between the pectoralis muscle and underneath the chest wall due to the remnant implant capsule 18 months after initial surgery. This indicated that the breast implants were inserted into the subpectoral dual pocket during the previous augmentation mammoplasty. The unintentional movement of the chest wall skin might have been the result of an abnormal adhesion of the pectoralis muscle and subcutaneous tissue.

Considering the burden of general anesthesia, other procedures to prevent recurrence, such as elimination of adhesion between the skin and muscle and placement of acellular dermal matrix or subcutaneous tissue local flap, can be performed under local anesthesia. Nonetheless, we considered that it would be very difficult to localize the adhesion site and remove the capsule entirely under local anesthesia. However, performing the procedure simultaneously with implant removal could eliminate unnecessary stress or expenses for the patient. This case suggests that breast animation deformity can appear even after breast implant removal. Capsulecto- 
my and repositioning of the pectoralis muscle to its original place can be considered during implant removal.

\section{NOTES}

\section{Conflict of interest}

No potential conflict of interest relevant to this article was reported.

\section{Ethical approval}

The study was performed in accordance with the principles of the Declaration of Helsinki.

\section{Patient consent}

The patients provided written informed consent for the publication and the use of their images.

\section{ORCID}

Simon Yang

Dae Hyun Lew

https://orcid.org/0000-0001-8333-2868

Tai Suk Roh

https://orcid.org/0000-0002-2625-5664

Seung Yong Song

https://orcid.org/0000-0001-8681-159X

https://orcid.org/0000-0002-3145-7463

\section{Supplemental material}

Supplementary materials can be found via https://doi.org/10.14730/ aaps.2020.02152.

\section{REFERENCES}

1. Hillard C, Fowler JD, Barta R, et al. Silicone breast implant rupture: a review. Gland Surg 2017;6:163-8.

2. Young VL. Guidelines and indications for breast implant capsulectomy. Plast Reconstr Surg 1998;102:884-91.

3. Roberts JM, Carr LW, Jones A, et al. A prospective approach to inform and treat 1340 patients at risk for BIA-ALCL. Plast Reconstr Surg 2019;144:46-54.

4. Swanson E. Evaluating the necessity of capsulectomy in cases of textured breast implant replacement. Ann Plast Surg 2020 Feb 25 [Epub]. https://doi.org/10.1097/SAP.0000000000002301.

5. Thomson HG. The fate of the pseudosheath pocket around silicone implants. Plast Reconstr Surg 1973;51:667-71.

6. Rockwell WB, Casey HD, Cheng CA. Breast capsule persistence after breast implant removal. Plast Reconstr Surg 1998;101:1085-8.

7. Dyrberg DL, Bille C, Gunnarsson GL, et al. Breast animation deformity. Arch Plast Surg 2019;46:7-15.

8. Alnaif N, Safran T, Viezel-Mathieu A, et al. Treatment of breast animation deformity: a systematic review. J Plast Reconstr Aesthet Surg 2019;72:781-8. 
Supplemental Digital Content 1. On physical examination, unintended motion of the medial side of the lower pole of the breast is observed when the patient is asked to contract the pectoralis muscle. 